\title{
Prehospital Management of Aortic Dissection
}

\author{
Andrej Preveden ${ }^{1,2}$, Slavica Majdevac², Mihaela Detki², Nikola Mladenović2, \\ Bogdan Okiljević ${ }^{1,2}$, Stamenko Šušak ${ }^{1,2}$
}

(1) University of Novi Sad, Medical Faculty, Novi Sad, Serbia

(2) Institute for Cardiovascular Diseases of Vojvodina, Sremska Kamenica, Serbia

Correspondence:

ANDREJ PREVEDEN

E:andrej.preveden@mf.uns.ac.rs

\section{ARTICLE INFO}

Received: 10 April 2019

Revision received: 20 May 2019 Accepted: 29 May 2019

Key words: aortic dissection, chest pain, prehospital care, medical therapy.

\section{BACKGROUND}

Although aortic dissection is not the most common condition in cardiology, its acute onset and high mortality rate require every health care provider to be familiar with the basic concept of its management. This is particularly important for the personnel that makes the initial contact with patient, whose goal is to rise a suspicion and recognize aortic dissection, as well as to safely transport the patient to a health center capable of providing the definite treatment.

\section{CLINICAL PRESENTATION}

Pain is the first and the most prominent symptom that occurs in over $90 \%$ of patients with aortic dissection. ${ }^{1,2}$ The pain usually localized in the chest or in the back, it has a sudden onset and an intensive, tearing or ripping character. ${ }^{3}$ The pain can migrate along the spine towards the lower back as the dissection extends distally. ${ }^{4}$ The pain presentation can vary depending on the localization of the dissection (Table 1).

Table 1. Association between dissection localization and pain character

\begin{tabular}{ll}
\hline Place of dissection & Pain localization \\
\hline Ascending aorta & Chest \\
\hline Aortic arch & Neck and lower jaw \\
\hdashline Descending aorta & Upper back (interscapular), spreading down the spine towards the \\
\hline
\end{tabular}

Copyright $\odot 2019$ Preveden et al. This is an open access article distributed under the Creative Commons Attribution License (CC BY), which permits unrestricted use, distribution, and reproduction in any medium, provided the original work is properly cited. This article should be cited as follows: Preveden A, Majdevac S, Detki M, Mladenović N, Okiljević B, Šušak S. Prehospital management of aortic dissection. Scr Med 2019;50(2):103-6. 
Considering the fact that such a severe pain can occur in a wide range of different acute conditions (Table 2), it is not a surprise that, in many cases, false diagnosis is made on initial contact with patient, out of which almost half is interpreted as acute coronary syndrome. ${ }^{6}$ The distinction between these two is that the pain in aortic dissection is strongest and most intensive at the very beginning, whereas ischemic pain usually progresses and intensifies over time. ${ }^{4}$

Table 2. Differential diagnosis of the acute chest pain ${ }^{7,8}$

\begin{tabular}{ll}
\hline \multicolumn{2}{l}{ Possible causes of the acute chest pain } \\
\hline Myocardial ischemia & Pneumothorax \\
\hline Pericarditis & Costochondritis \\
\hline Aortic dissection & Trauma \\
\hline Pulmonary thromboembolism & Esophageal reflux \\
\hline Pneumonia & Peptic ulcer \\
\hline
\end{tabular}

Another common symptom in patients with aortic dissection is syncope, which usually indicates that the dissection has spread into the brachiocephalic trunk and carotid arteries. Other neurological symptoms may include paraplegia, vocal cord paralysis, and Horner's syndrome., ${ }^{2,9}$

The final diagnosis can only be made in hospital conditions using imaging techniques such as echocardiography, computerized tomography and magnetic resonance. ${ }^{10}$ Nevertheless, it is important to pay attention to particular signs in physical examination that can help in differential diagnosis of aortic dissection in prehospital conditions.

Hypertension is the most common sign in patients with aortic dissection. ${ }^{2}$ It is important to measure the blood pressure on both arms, because the specific sign for aortic dissection is the difference between left and right arm blood pressure of $20 \mathrm{mmHg}$ or more. ${ }^{1}$ Every part of the body should be examined in search for signs of arterial insufficiency, primarily the absence of pulses. ${ }^{2,11}$ Auscultation should focus on search for diastolic murmur, which is a sign of aortic regurgitation that can develop with the dissection of the ascending aorta. ${ }^{7,12}$

If possible, it is desirable to perform an ECG, mainly in order to exclude the acute coronary syndrome.

\section{PREHOSPITAL MANAGEMENT}

Considering the nature and the complexity of aortic dissection, its definite treatment is possible only in hospital conditions. Hence, the main goal of prehospital management should be patient stabilization, initiation of medical therapy and safe transport to specialized health center.

It is desirable to talk to patient and acquire anamnestic data during the first contact with patient. In case of a consciousness deterioration later on, this may be the only chance to gather information about medical history and comorbidities from the patient himself.

Next step in the management is the application of oxygen support via the breathing mask to prevent organ damage. Further on, providing at least one secure venous line is mandatory. It is important to monitor all vital functions during transport, including heart rhythm and diuresis, in order to have a continuous insight into the patient's current state and in case of a deterioration react appropriately., 13,14

Blood pressure control is the main goal of the medical treatment in aortic dissection. Systolic blood pressure should be kept between 100$120 \mathrm{mmHg},{ }^{10,12}$ whereas the target heart rate is 60 beats per minute. 5 The ideal medication for reaching these parameters is beta-blocker, so the treatment should be initiated with intravenous administration of esmolol, metoprolol or labetalol. Caution should be taken when aortic regurgitation is present, because of the beta-blockers effect on diastole prolongation. ${ }^{7,11,12}$

If there are contraindications for beta-blockers, or the desired heart rate reduction cannot be achieved, non-dihydropyridine calcium channel blockers verapamil or diltiazem can be administered. ${ }^{11,15}$

If the blood pressure remains elevated despite the heart rate reduction, intravenous vasodilators, such as nitroglycerin, should be used. ${ }^{16,17}$ Most of the guidelines clearly point out that vasodilators should not be used before the target heart rate is achieved, because otherwise compensatory tachycardia may be induced, which would increase the stress on the aortic wall and cause the spreading of the dissection. ${ }^{15,17}$ 
Alongside the blood pressure control, pain management is mandatory in the acute phase of aortic dissection. For this, intravenous administration of opiates is recommended. Morphine is the first choice, because it not only reduces pain, but also inhibits the sympathetic stimulation as well, which additionally reduces the stress on the aortic wall. ${ }^{3,17}$

One should always have in mind the fact that every patient with an acute dissection of the aorta is likely to develop hemodynamic instability and eventually shock. If that occurs, intravenous fluid replacement with crystalloids should be initiated immediately. In case of a refractory hypotension despite the adequate fluid replacement, vasopressor therapy with noradrenalin or phenylephrine is indicated. Development of shock in patient with aortic dissection is a probable sign of pericardial effusion and cardiac tamponade, so the patient should be intubated and mechanically ventilated with the appropriate sedation. ${ }^{3,11}$

\section{CONCLUSION}

Proposed algorithm for the prehospital management of aortic dissection is shown in Figure 1.

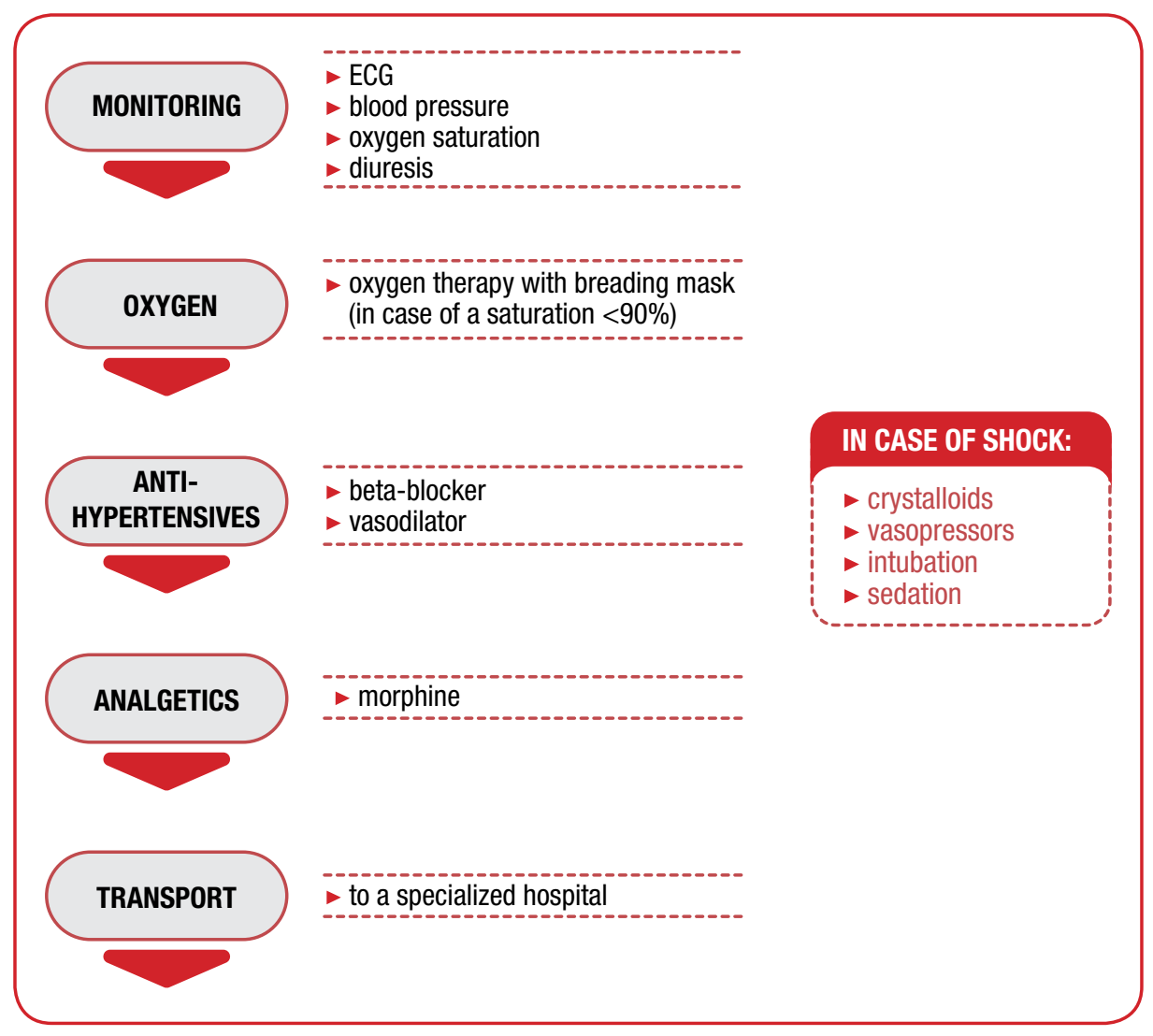

Figure 1: Proposed algorithm for the prehospital management of the aortic dissection

None.

None. 


\section{REFERENCES}

1. Mészáros I, Mórocz J, Szlávi J, Schmidt J, Tornóci L, Nagy L, et al. Epidemiology and clinicopathology of aortic dissection. Chest 2000;117(5):1271-8.

2. Hagan PG, Nienaber CA, Isselbacher EM, Bruckman D, Karavite DJ, Russman PL, et al. The international registry of acute aortic dissection (IRAD): new insights into an old disease. JAMA 2000;283(7):897-903.

3. Dixon M. Aortic dissection or MI? It could be both. Emergency Med 2014;4(4):199.

4. Pons PT, Markovchick VJ, editors. Prehospital care pearls and pitfalls. Shelton, CT, USA: People's Medical Publishing House; 2012.

5. Crawford ES. The diagnosis and management of aortic dissection. JAMA 1990;264:2537-41.

6. Zhan S, Hong S, Shan-Shan L, Chen-Ling Y, Lai W, Dong-Wei S, et al. Misdiagnosis of aortic dissection: experience of 361 patients. J Clin Hypertens 2012;14(4):256-60.

7. Jameson JL, Fauci AS, Kasper DL, Hauser SL, Longo DL, Loscalzo J, editors. Harrison's principles of internal medicine. 2oth ed. New York: McGraw-Hill Education; 2018.

8. Greaves I, Porter K. Oxford handbook of pre-hospital care. Oxford: Oxford University Press; 2007.

9. Long B, Koyfman A. Vascular causes of syncope: an emergency medicine review. J Emerg Med 2017;53(3):322-32.
10. Nienaber CA, Clough RE. Management of acute aortic dissection. Lancet 2015;385:800-11.

11. Li JZ, Eagle KA, Vaishnava P. Hypertensive and acute aortic syndromes. Cardiol Clin 2013;31(4):493-501.

12. The Task Force for the Diagnosis and Treatment of Aortic Diseases of the European Society of Cardiology (ESC). 2014 ESC Guidelines on he diagnosis and treatment of aortic diseases. Eur Heart J 2014;35:2873926.

13. Henry MC, Stapleton ER, Edgerly D. EMT prehospital care. St. Louis: Mosby Jems/Elsevier; 2010.

14. Caroline NL, MacDonald RD, Burgess RJ. Nancy Caroline's emergency care in the streets. Sudbury: Jones and Bartlett; 2010.

15. Hiratzka LF, Bakris GL, Beckman JA, Bersin RM, Carr VF, Casey DE, et al. 2010 ACCF/AHA/AATS/ACR/ ASA/SCA/SCAI/SIR/STS/SVM guidelines for the diagnosis and management of patients with thoracic aortic disease. Circulation 2010;121:e266-369.

16. Wittels K. Aortic emergencies. Emerg Med Clin N Am 2011; 29(4):789-800.

17. Suzuki T, Eagle KA, Bossone E, Ballotta A, Froehlich JB, Isselbacher EM. Medical management in type B aortic dissection. Ann Cardiothorac Surg 2014;3(4):413-7. 